Türkiye Jeoloji Bülteni
Geological Bulletin of Turkey
$63(2020) 125-136$
doi: $10.25288 / \mathrm{tjb} .626743$

\title{
GAP'ın En Büyük Sulama Sahasında Jeotermal Sulardan Kaynaklanan Potansiyel Ağır Metal Kirliliğinin Araştırılması
}

Investigation of Potential Heavy Metal Pollution Caused by Geothermal Waters in GAP's Largest

Irrigation Area

\author{
Perihan Derin $^{1 *} \mathbb{D}$, Ayşegül Demir Yetiş² ${ }^{\mathbb{D}}$, M. İrfan Yeşilnacar ${ }^{3} \mathbb{D}$, Pelin Yapıcıoğlu $^{3} \mathbb{D}$ \\ ${ }^{1}$ Harran Üniversitesi, Fen Bilimleri Enstitüsü, Çevre Mühendisliği Anabilim Dal, 63000 Şanlıurfa \\ ${ }^{2}$ Bitlis Eren Üniversitesi, Mühendislik Fakültesi, Çevre Mühendisliği Bölümü, 13000 Bitlis \\ ${ }^{3}$ Harran Üniversitesi, Mühendislik Fakültesi, Çevre Mühendisliği Bölümü, 63000 Şanlıurfa
}

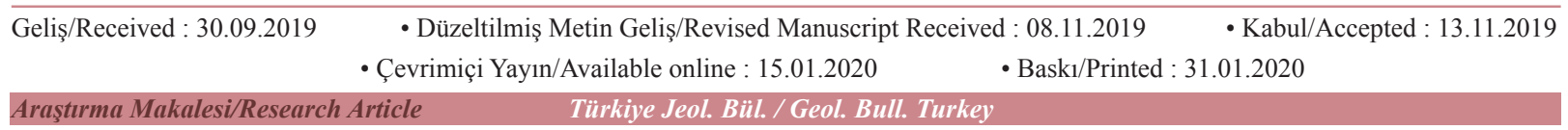

Öz: Karaali jeotermal alanı, Türkiye'deki jeotermal alanlardan biri olup, Güneydoğu Anadolu Bölgesi’nde Şanlıurfa ilinin $45 \mathrm{~km}$ güneydoğusunda ve Akçakale grabeni içerisindeki Karaali köyünde yer almaktadır. Karaali jeotermal alanı ülkemizin kalkınmasında çok önemli tarımsal potansiyele sahip Harran Ovası'nda bulunması, Şanlıurfa ilinin tek termal turizmi ve sera ısıtma kaynağı olması sebebiyle büyük önem taşımaktadır. Jeotermal kaynakların kullanıldıktan sonra doğrudan ya da dolaylı olarak denetimsiz bir şekilde en yakın drenaj kanallarına deşarj edilmesi, yeraltı suları ile beraberinde toprağı ve bitkileri ağır metal kirlenmesi anlamında olumsuz etkilemektedir. Bu çalışma kapsamında, jeotermal kaynaklı ağır metal kirliliğinin insan sağlığı bakımından doğrudan ve dolaylı maruziyeti tespit etmek amacıyla Karaali jeotermal akışkanı (KJ) ve yakınındaki drenaj kanalları (D9, D10, D11, D12 ve D13) olmak üzere toplamda 6 noktadan Şubat ve Ekim 2018 tarihleri arasında mevsimsel örnekleme yapılmıştır. Su örneklerinin $\mathrm{Al}, \mathrm{As}, \mathrm{Co}, \mathrm{Cr}, \mathrm{Fe}, \mathrm{Mn}, \mathrm{Mo}, \mathrm{Ni}, \mathrm{Pb}, \mathrm{Sb}$, Se ve V gibi ağır metal parametreleri belirlenmiştir. Sonuç olarak drenaj kanallarındaki suların tarımsal amaçlı sulama suyu olarak yeniden kullanılması için dikkate alınması gereken ilgili yönetmelikteki değerleri $\mathrm{Al}, \mathrm{Cr}, \mathrm{Fe}, \mathrm{Mo}, \mathrm{Ni}$, Se ve $\mathrm{V}$ parametrelerinde aştığı tespit edilmiştir. Bunun yanında drenaj kanallarının yakınındaki iki kuyuda ise TSE 266, EPA ve WHO içme suyu kriterlerine göre sınır değeri Al ve Fe parametrelerinde aştığı saptanmıştır. Nihai olarak drenaj kanallarındaki Al, Cr, Fe, Mo, Ni, Se ve V gibi ağır metal kirliliği, yeraltı sularını sadece Al ve Fe bakımından etkilemiştir. Sulama suyunun yeniden kullanılması ile toprak, bitki ve yeraltı suyuna taşınan ağır metal kirliliği nedeniyle insan sağlığına olacak dolaylı maruziyetin şu an için yeraltı suyunun tüketimi ile doğrudan olacak maruziyetten daha etkili olduğu sonucuna varılmıştır. Ancak ilerleyen zamanda yeraltı sularında ağır metal bakımından sınır değerleri aşacak parametrelerde artışın söz konusu olması da muhtemeldir.

Anahtar Kelimeler: Jeotermal sular, ağır metal kirlenmesi, Harran Ovası, Karaali, Şanlıurfa

\begin{abstract}
The Karaali Geothermal field, one of the geothermal areas in Turkey, is located $45 \mathrm{~km}$ south-east of Şanlurfa province in southeastern Anatolia. It also covers the area including Karaali village within the Akçakale graben. In addition, Karaali geothermal area is of great importance for Şanluurfa not only because of thermal tourism and being a greenhouse heating source, but also because it is located in the Harran Plain which has very important agricultural potential for the development of Turkey. In recent studies, direct or indirect uncontrolled discharge of geothermal waters into the nearest drainage channels was shown to adversely affect soil and plants in terms of heavy metal contamination This study aims to determine the direct and indirect exposure to heavy metal pollution originating in geothermal waters with respect to human health. Seasonal sampling was carried out between


February - October 2018 at 6 points in total, including the drainage channels (D9, D10, D11, D12 and D13) in the vicinity of Karaali geothermal fluid (KJ). Heavy metal parameters were measured such as $\mathrm{Al}, \mathrm{As}, \mathrm{Co}, \mathrm{Cr}, \mathrm{Fe}, \mathrm{Mn}$, $\mathrm{Mo}, \mathrm{Ni}, \mathrm{Pb}, \mathrm{Sb}$, Se and $\mathrm{V}$. As a result, it was concluded that the sampling values exceed the values for $\mathrm{Al}, \mathrm{Cr}, \mathrm{Fe}$, $\mathrm{Mo}, \mathrm{Ni}$, Se and $V$ in the regulations that should be taken into consideration for the reuse of water in the drainage channels. Additionally, in nearby 2 groundwater wells (K7 and K8), the limit values were exceeded for Al and Fe parameters according to TSE 266, EPA and WHO drinking water criteria. Finally, heavy metal pollution in the drainage channels affected the wells only in terms of Al and Fe. It was also concluded that the indirect exposure impact due to heavy metal that is carried to soil, plants and groundwater by the re-use of irrigation water is more serious for human health than direct exposure caused by groundwater consumption However, over a certain period of time an increase in parameters exceeding the limit values in terms of heavy metal may also occur.

Keywords: Geothermal water, Harran Plain, heavy metal pollution, Karaali, Şanluurfa.

\section{GíRiş}

Yüzey ve yeraltı sularındaki inorganik kirleticilerin en önemli kaynağını ağır metaller oluşturur. Ağır metallerin sucul ortamlardaki bulunuş özellikleri, taşınım ve birikim mekanizmaları birçok farklı parametreye bağlı olup, oldukça karmaşık proseslerdir (Güven ve Öztürk, 2005). Ağır metaller çevreye doğal kaynaklı ve insan aktiviteleri sonucunda (antropojenik) olmak üzere iki farklı yoldan bırakılırlar (Sabiha-Javied vd., 2009; Derin, 2019). Bazı ağır metaller çevreye yayıldıkça, bulundukları ortamdaki derişimlerine bağlı olarak bitki gelişimi, hayvan ve insan yaşamı üzerinde olumsuz etkilere sebep olabilirler. Ağır metallerin ve metal(loid) içeren bileşiklerin birçoğu zehirlidir, bu sebeple çok küçük derişimlerde dahi istenmeyen etkilere ve sorunlara neden olabilirler (Kara, 2005; Arora vd., 2008; Derin, 2019). Bu kirleticilerin topraktaki ve canlı organizmalardaki birikiminin etkileri k1sa sürede görülemeyebilir, bu yüzden ağır metal birikiminin yakından takip edilmesi gereklidir.

Harran Ovası'nda 1995 yılında yüzey sulamasının başlamasıyla birlikte yoğun tarımsal faaliyetler, aşırı ve kontrolsüz sulama ve yetersiz drenaj sisteminden dolayı önemli çevresel sorunların ortaya çıktığı rapor edilmiştir (Yeşilnacar vd., 2007). Bu çalışmanın amacı, ovada yer alan Karaali jeotermal akışkanın kullanıldıktan sonra drenaj kanallarına kontrolsüz bir şekilde deşarj edilmesi ile drenaj kanallarındaki sulama suyuna ve bu drenaj kanallarına yakın kuyulara olan etkisini belirlenmesidir.

\section{MATERYAL ve METOT}

\section{Çalışma Alanının Konumu}

Şanlıurfa ili sınırları içerisinde bulunan Harran Ovası, 141500 ha sulama alanı, $3700 \mathrm{~km}^{2}$ drenaj alanı ve $1500 \mathrm{~km}^{2}$ ova alanıyla GAP'in en büyük ovasıdır (Yeşilnacar vd., 2007). Şanlıurfa ilinde Karaali ve Kabahaydar olmak üzere iki adet jeotermal alan bulunmakta olup, Karaali jeotermal alanı Harran Ovası sınırları içerisinde yer almaktadır (Şekil 1). Karaali jeotermal alanı, Güneydoğu Anadolu Bölgesi’nde Şanlıurfa ilinin $45 \mathrm{~km}$ güneydoğusunda ve Akçakale grabeni içerisindeki Karaali köyündedir. Karaali jeotermal alanında 1993 yılından beri 17'si özel idare, 15'i özel sektör tarafindan olmak üzere toplam 32 adet jeotermal arama amaçlı sondaj çalışması gerçekleştirilmiş, 39-58 ${ }^{\circ} \mathrm{C}$ arasında değişen sıcaklıkta akışkan üretimi sağlanmıştır. 


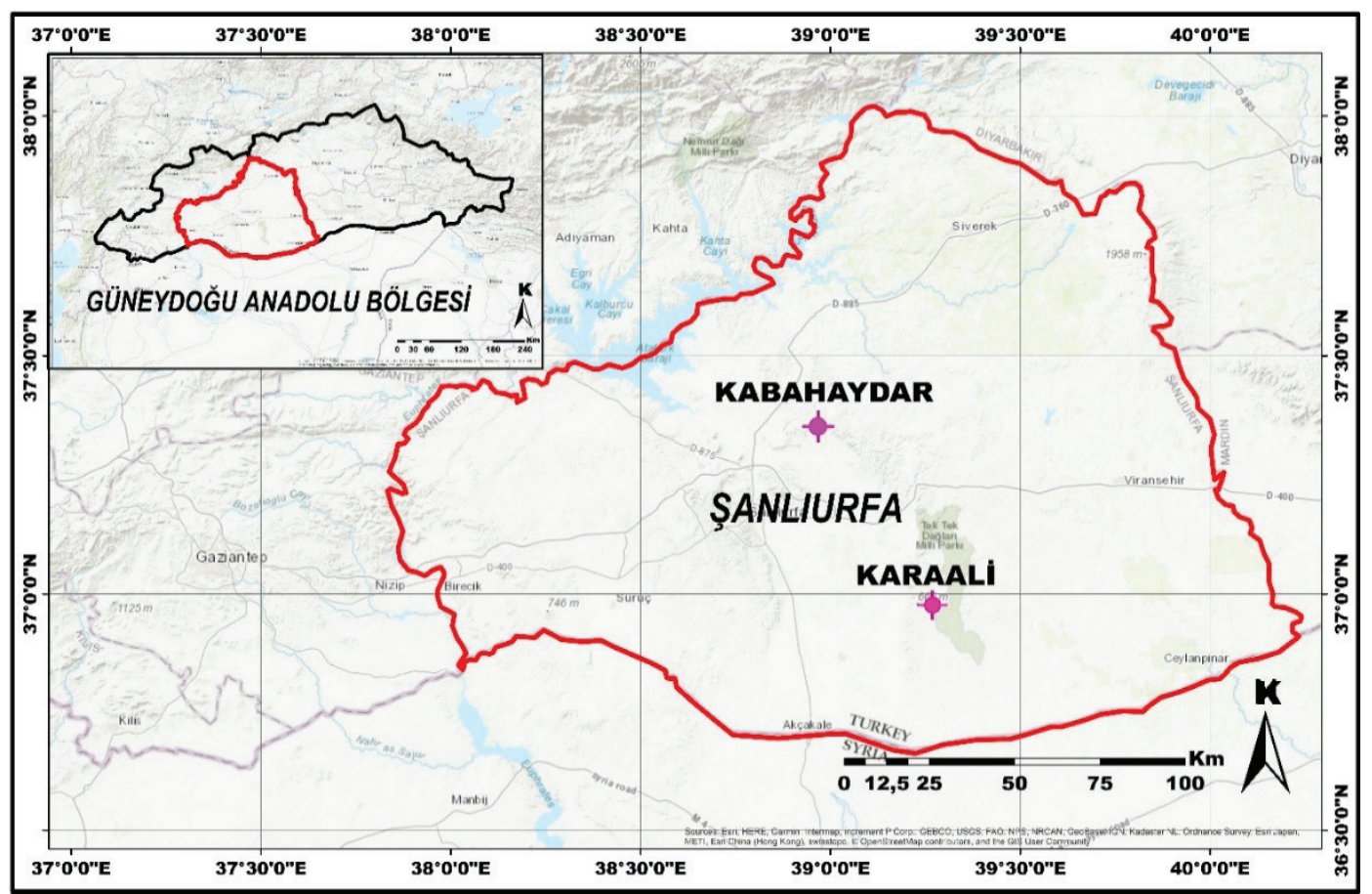

Şekil 1. Şanlıurfa ili jeotermal kaynakları.

Figure 1. Geothermal fields in Şanliurfa.

\section{Jeolojik ve Tektonik Özellikler}

Karaali jeotermal sahas1, alüvyon dolgulu düzlükler ile aralarında yüzeylenen Eosen ve daha genç çökellerden meydana gelen ve Akçakale grabeni diye tanımlanan graben içerisinde yer almaktadir.

\section{Hidrojeolojik Özellikler}

GAP idaresinin kurulması ile birlikte Harran Ovası'nda yapılan çalışmalar hız kazanmıştır. Harran ovasındaki sulama 1993 yılına kadar tamamen yeraltı suyu ile sağlanmıştır. Karaali jeotermal alanının yer aldı̆̆ı Harran Ovası'nda 1995 yilında yüzey sulamasına geçilmesine rağmen alan hala yeraltı sularına bağlıdır. Harran Ovası'nda, sulama amaçlı olarak hem özel hem de kamu kurumları tarafından açılmış yaklaşık 10000 adet kuyu bulunmaktadır. Karaali jeotermal alanı akifer kaynağını, çevresinde yüzlek veren Paleosen yaşlı tortul kayaçlar taşımaktadır.
Aynı zamanda, alanda bariyer görevini de göstermektedir. Özellikle Paleosen birimler üzerinde yüzlek veren kireçtaşları ise yeraltı suyu açısından zengindir. Karaali jeotermal alanının çevresinde yüzlek veren Eosen yaşlı kireçtaşları karstik özelliğe sahiptir (Yetiş vd., 2019). Ovanın kuzeyinde, kuzeydoğusunda ve kuzey batısında Eosen yaşlı kireçtaşları, ovanın doğusunda geniş bir alanda ise Miyosen kireçtaşları, batısında ise Oligo-Miyosen yaşlı kireçtaşları yüzlek vermiştir (Baba vd., 2015).

\section{Örnekleme Çalışmaları ve Metodoloji}

Bu çalışmada, Harran Ovası'nda Şubat ve Ekim 2018 tarihleri arasında 4 dönem olacak şekilde gerçekleştirilmiştir. Karaali jeotermal kaynağından (KJ) 1 adet (sera ve kaplıca turizminde kullanılan sudan), kaynağa yakın farklı drenaj kanallarındaki sulardan (D9, D10, D11, D12 ve D13) 5 adet olmak üzere toplamda 6 ayrı noktadan örnekleme 
yapılmıştır. Bunun yanında OSİB (2017) tarafından yapılan çalışmada drenaj kanallarının potansiyel etkisi altında olan 2 adet yeraltı suyunun (K7 ve K8) analiz sonuçları dikkate alınarak değerlendirilmiştir. Çalışma kapsamında, örnekleme noktalarının seçimlerinde dikkate alınan hususlara ait bilgiler Çizelge 1'de detaylı olarak yer almaktadır. Drenaj kanallarındaki sular, Karaali jeotermal kaynağı ile tarımsal sulamadan dönen sulardan meydana gelmektedir. Kaplıca ve sera 1sitılmasında kullanılan jeotermal kaynaklı suların denetimsiz bir şekilde Harran Ovası'nda bulunan en yakın drenaj kanalına deşarj edildiği ve örnekleme noktalarından biri olan D11 örnekleme noktası özellikle jeotermal suyun drenaj kanalına ilk karıştı̆̆ 1 nokta olması sebebiyle seçilmiştir.
Alınan su numunelerinde; $\mathrm{Al}, \mathrm{As}, \mathrm{Co}, \mathrm{Cr}$, $\mathrm{Fe}, \mathrm{Mn}, \mathrm{Mo}, \mathrm{Ni}, \mathrm{Pb}, \mathrm{Sb}, \mathrm{Se}$ ve $\mathrm{V}$ gibi ağır metal parametrelerinin ölçümleri yapılmıştır. Su örnekleriAPHA(1998) “1060 C. Sample stroge and preservation" metoduna göre $250 \mathrm{ml}$ 'lik polietilen şişelere alınarak, nitrik asitle muamele edilmiş ve $+4{ }^{\circ} \mathrm{C}$ 'de muhafaza edilerek ölçümü yapılmak üzere akredite laboratuvara gönderilmiştir. Ağır metal parametrelerinin ölçümleri indüktif eşleşmiş plazma-optik emisyon spektrometresi (ICP-OES) cihazı ile ISO 17025 kalite sistemiyle akredite edilmiş laboratuvarda yaptırılmıştır. Örnekleme yapılan noktaların koordinat ve lokasyon bilgileri Çizelge 1'de ve örnekleme noktalarının konumu Şekil 2'de sunulmuştur.

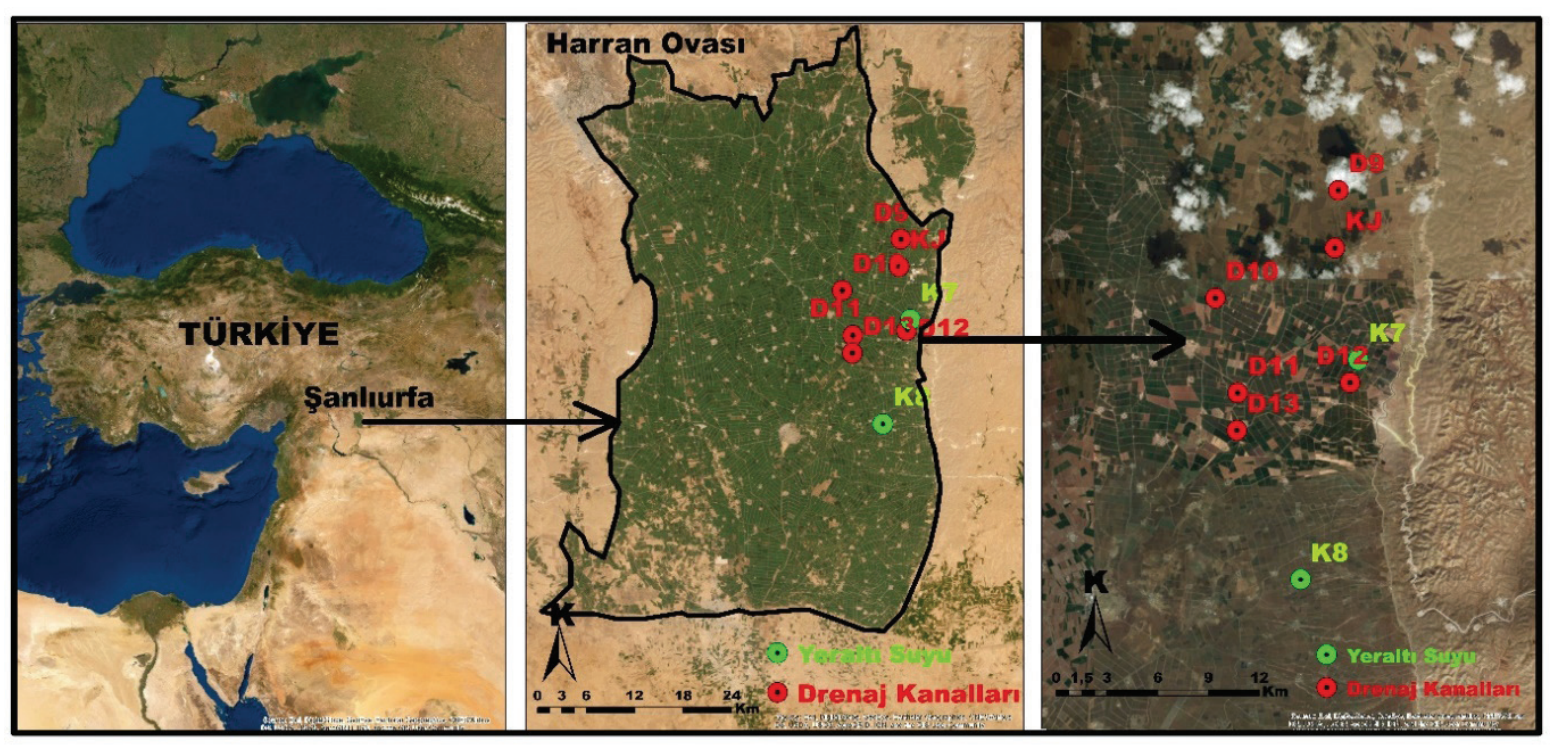

Şekil 2. Çalışma alanına ait coğrafik görünüm ve örnekleme noktalarının konumu.

Figure 2. Geographic view of the study area and location of sampling points. 
Çizelge 1. Örnekleme noktalarına ait lokasyonlar ve seçilme nedenleri.

Table 1. Location of sampling points and reasons for selection.

\begin{tabular}{ccccc}
\hline \multirow{2}{*}{ Örnek No } & Lokasyon & Seçilme Nedeni & \multicolumn{2}{c}{ Koordinat } \\
\cline { 3 - 5 } & \multirow{2}{*}{ Yaşar } & Jeotermal kaynakların membasında yer almasından dolayı seçilmiştir. & 513607 & 4099237 \\
D10 & Vergili & HT 10-1 ana tahliye kanalı üzerinde olması nedeni ile seçilmiştir. & 507815 & 4094181 \\
D11 & Küpeli & Jeotermal kaynaklar sonrası durumun tespiti amaciyla seçilmiştir. & 508870 & 4089751 \\
D12 & Vergili & Firat suyuyla sulanan arazilerden elde edilen taze drenaj suyunu temsil & 514174 & 4090239 \\
D13 & Banarlı & etmektedir. & 508830 & 4087997 \\
KJ & Karaali & Karaali jeotermal alanında sera ve kaplıca turizminde kullanılan suyu temsil & 513439 & 4096533 \\
K7 & Olgunlar & Örnekleme noktalarının orta kesimindeki kirliliği temsil etmektedir. & 514560 & 4091310 \\
K8 & Yaygılı & Bütün örnekleme noktalarından gelen kirliliği temsil etmektedir. & 511860 & 4081017 \\
\hline
\end{tabular}

Drenaj kanallarındaki örnekleme noktalarından elde edilen ağır metal verileri, taslak "Sulama Sularının Kalitesi ve Kullanılmış Suların Yeniden Kullanılması Hakkında Yönetmelik" ekinde yer alan EK-1'in Tablo 2 "Sulamada Kullanılacak Sularda Kabul Edilebilen Maksimum Eser Element Konsantrasyonları" listesinde yer alan kriterlere göre mukayese edilmiştir. Drenaj kanallarında ölçülen ağır metal düzeylerinin yeraltı suyuna, toprağa ve bitkiye olan dolaylı etkisi değerlendirilmiştir. Ayrıca OSİB (2017) tarafindan tamamlanan "Sulamadan geri dönen suların kontrolü ve yeniden kullanımı için iyileştirilmesinin araştırılması projesi” kapsamında drenaj kanallarının yakınındaki yeraltı sularında ölçülmüş ağır metal konsantrasyonlarından yola çıkarak yeraltı sularına doğrudan etkisi de içme suyu kriterlerine göre irdelenmiştir. K7 ve K8 no'lu kuyulara ait Mart ve Ekim 2016 tarihlerinde yapılan ölçümler, TSE 266 (2005), EPA (2012) ve WHO (2017) gibi ulusal ve uluslararas1 mevzuatlardaki içme suyu kriterlerine göre mukayese edilerek değerlendirilmiştir.

\section{BULGULAR VE TARTIŞMA}

Harran Ovası'ndaki drenaj kanallarında Şubat ve Ekim 2018 tarihleri arasında mevsimsel olarak izlenen jeotermal kaynak ve drenaj kanallarındaki 6 farklı örnekleme noktasina ait Al, As, Co, $\mathrm{Cr}, \mathrm{Fe}, \mathrm{Mn}, \mathrm{Mo}, \mathrm{Ni}, \mathrm{Pb}, \mathrm{Sb}$, Se ve $\mathrm{V}$ gibi ağır metal parametrelerinin ölçümleri yapılmıştır. Örnekleme noktalarından elde edilen veriler "Sulama Sularının Kalitesi ve Kullanılmış Suların Yeniden Kullanılması Hakkında Yönetmelik" taslak ekindeki sınır değerlerle mukayese edilerek değerlendirilmiştir. Bunun yanında tarımsal üretim amaçlı drenaj kanallarındaki bu suların çiftçiler tarafından yeniden kullanımının toprağa, bitkiye ve yeraltı suyuna etki ederek ağır metal bakımından insan sağlığına olan dolaylı etkisi irdelenmiştir.

Drenaj kanallarındaki sular, Karaali jeotermal kaynak suları ile tarımsal sulamadan dönen sulardan meydana gelmektedir. Dolayısıla insana olan doğrudan maruziyetin boyutlarını ortaya koyma adına OSIBB (2017) tarafindan yapılan çalışmada akışın kuzeyden güneye olduğu düşünüldüğünde (Çelik ve Gülersoy, 2013) drenaj kanallarının potansiyel etkisi altında olan K7 ve K8 no'lu kuyulardan alınan verilerin de ağır metal sonuçları içme suyu kriterlerine göre değerlendirilmiştir.

Drenaj kanallarında ölçülen ağır metal parametreleri için minimum ve maksimum değerler ve sulamada kullanılacak sularda 
kabul edilebilen maksimum eser element konsantrasyonları Çizelge 2'de görülmektedir. Buna göre Al için 1 adet örnekleme noktasında (D11), Cr için 4 örnekleme noktasında (D9, D10, D11 ve D13), Fe için 5 örnekleme noktasında (D9, D10, D11, D12 ve Karaali), Mo için 2 örnekleme noktasında (D11 ve Karaali), Ni için 2 örnekleme noktasında (D9 ve D11), Se ve V için tüm noktalarda ölçülen değerler Çizelge 2'de yer alan toplam 7 parametrede sinır kriterlerini aşmıştır. As, $\mathrm{Co}, \mathrm{Mn}$ ve $\mathrm{Pb}$ değerleri açısından ise Çizelge 2'de yer alan sınır değerler aşılmamıştır. $\mathrm{Sb}$ parametresi için mevzuatta sınır değer yer almadığ 1 için değerlendirme yapılamamıştır.
Harran ovasinda tarımsal sulamadan sonra drenaj kanallarına verilen suların sulamada yeniden kullanıldığg dikkate alındığında ölçüm yapılan bütün ağır metal parametreleri bakımından örnekleme noktaları arasında en kirli olan noktanın D11 no'lu nokta, en temiz noktanın ise D12 no'lu nokta olduğu tespit edilmiştir (Şekil 3). D11 no'lu nokta jeotermal kaynaklar sonrasında gelen sular ile sulamadan dönen kirli sulardan oluşmaktayken, D12 no'lu nokta Firat suyuyla sulanan arazilerden elde edilen taze nispeten daha temiz drenaj suyunu temsil etmektedir.

Çizelge 2. Drenaj kanallarında izleme sonuçlarına ait minimum (min) ve maksimum (max) değerler ile kalite sınıfları ve nihai durumu.

Table 2. Minimum and maximum values of monitoring results in drainage channels, quality classes and final status.

\begin{tabular}{|c|c|c|c|c|}
\hline $\begin{array}{c}\text { Parametre } \\
(\mathrm{mg} / \mathrm{L})\end{array}$ & $\begin{array}{c}\text { Min Değer } \\
\text { (Gözlenen Nokta-Dönem) }\end{array}$ & $\begin{array}{c}\text { Max Değer } \\
\text { (Gözlenen Nokta-Dönem) }\end{array}$ & $\begin{array}{c}\text { Sinır Değer } \\
(\mathrm{mg} / \mathrm{L})\end{array}$ & Nihai Durum \\
\hline $\mathrm{Al}$ & 0,209 (D12-Ekim) & 8,827 (D11-Haziran) & 5 & Aşıld 1 \\
\hline As & 0,00001 (D10-Ağustos) & 0,00081 (D11-Şubat) & 0,1 & Aşılmadı \\
\hline Co & 0,00010 (D11-Haziran) & 0,0008 (Karaali-Haziran) & 0,05 & Aşılmadı \\
\hline $\mathrm{Cr}$ & 0,0001 (D9-Haziran) & 0,632 (D11-Şubat) & 0,1 & Aş1ld 1 \\
\hline $\mathrm{Fe}$ & 0,019 (Karaali-Ağustos) & 57,58 (D10-Ekim) & 5 & Aşıld 1 \\
\hline $\mathrm{Mn}$ & 0,014 (Karaali-Haziran) & 0,156 (D11-Haziran) & 0,2 & Aşılmadi \\
\hline Mo & 0,000136 (D11-Haziran) & 0,757 (Karaali-Şubat) & 0,01 & Aş1ld1 \\
\hline $\mathrm{Ni}$ & 0,00017 (D9-Ekim) & 0,331 (D9-Şubat) & 0,2 & Aş1ld1 \\
\hline $\mathrm{Pb}$ & 0,0001 (Karaali-Ağustos) & 0,728 (D11-Şubat) & 3 & Aş1lmadi \\
\hline $\mathrm{Sb}$ & 0,00014 (D11-Haziran) & 0,531 (D13-Şubat) & - & - \\
\hline $\mathrm{Se}$ & 0,00017 (D9-Ekim) & 0,331 (D9-Şubat) & 0,02 & Aş1ld1 \\
\hline $\mathrm{V}$ & 0,719 (D12-Ağustos) & 1,606 (Karaali-Ağustos) & 0,1 & Aşıld 1 \\
\hline
\end{tabular}




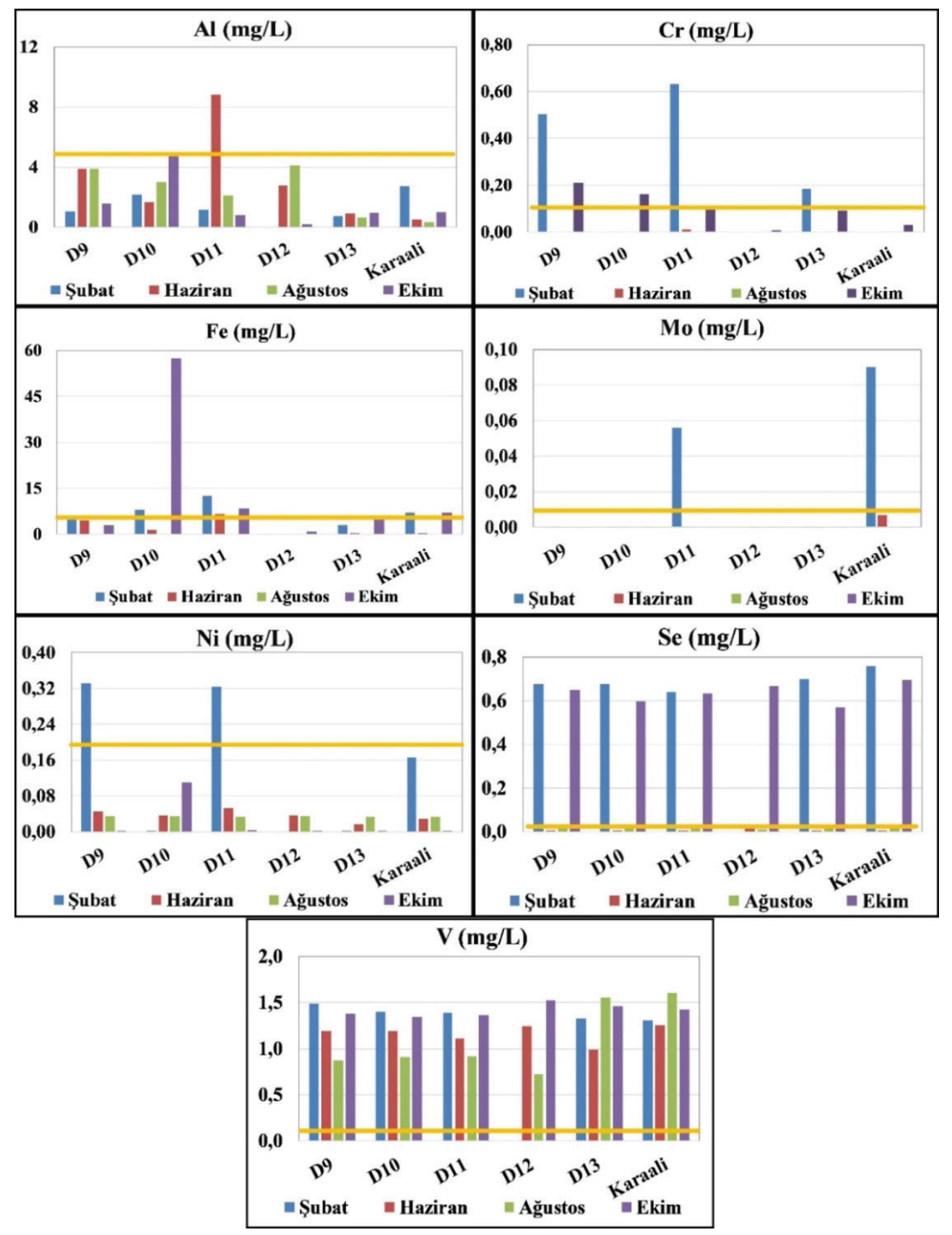

Şekil 3. Ağır metaller bakımından sınır değerleri aşan izleme sonuçlarının Karaali jeotermali ve drenaj kanallarındaki örnekleme noktalarına göre dönemsel değişimi.

Figure 3. Periodic change in monitoring results exceeding the limit values for heavy metals according to sampling points in Karaali geothermal field and drainage channels. 
Jeotermal kaynakların sonrasında özellikle bahçe sulaması ve kaplıca turizminden çıkan sularda yapılan Karaali örneklemesinde Fe, Mo, Se ve V olmak üzere 4 parametre bakımından kirlilik olduğu görülmektedir. Dolayısıyla jeotermal kaynaktan gelen suyun; bahçe sulamasinda, kaplica turizminde ve sulamada kullanıldıktan sonra ağır metal değerlerinde artış olduğu ve böylece kirlendiği ifade edilebilir. Diğer parametrelerin izleme sonuçlarının drenaj kanallarına ait örnekleme noktalarına ve Karaali jeotermal örnekleme noktasına göre dönemsel değişimine ait detay Şekil 3’te sunulmuştur. $\mathrm{Fe}$ parametresinin dönemsel değişimi değerlendirilecek olursa D10 no'lu örnekleme noktasında Ekim döneminde sınır değer aşılmıştır. D10 no'lu nokta HT 10-1 ana tahliye kanalı üzerinde bulunup, sulamada dönen suları kullanan sulama birliklerinin drenaj sularını toplamaktadır. Bu noktada özellikle Ekim döneminde Fe değerinin yüksek çıkmasının sebeplerinin çevreden taşınan volkanik kayaçlar ve kireçtaşlarına bağlı olduğu düşünülmektedir (OSİB, 2017). Ayrıca suya doygun topraklarda demir iyonlarının derişiminin artması ve kullanılan pesitisitin drenaj kanallarına yüzey akışla taşınması ile de açıklanabilir (Bahçeci, 2019). Mo parametresinin dönemsel değişimi değerlendirilecek olursa D11 ve Karaali örnekleme noktalarında Şubat döneminde sınır değer aşılmıştır. Karaali örnekleme noktası jeotermal sahasında sera ve kaplica turizminde kullanılan sudan oluşmaktayken D11 ise jeotermal kaynaklar sonrası durumun tespiti amaciyla seçilen noktadan oluşmaktadır. Bu noktalarda jeotermalden çıkan sıcak suyun volkanik kayaçları ve kireçtaşlarını çözmesine bağlı olarak Mo değerini etkilediği düşünülmektedir (OSİB, 2017). $\mathrm{Ni}$ ve $\mathrm{Cr}$ parametrelerinin dönemsel değişimi değerlendirilecek olursa D9 ve D11 no'lu (Cr'da Karaali) örnekleme noktalarında Şubat döneminde sınır değer aşılmıştır. D9 no'lu nokta jeotermal kaynakların membasında ve
D11 ise jeotermal kaynaklar sonrası durumun tespiti amacıyla seçilen noktadır. Bu noktalarda özellikle jeotermalden çıkan sıcak suyun volkanik kayaçları ve kireçtaşlarını çözmesine bağlı olarak $\mathrm{Ni}$ ve alaşımı olan $\mathrm{Cr}$ değerlerini etkilediği düşünülmektedir (OSİB, 2017).

Drenaj kanallarında ölçüm yapılan 12 adet ağır metal parametresinin 5 drenaj kanalındaki durumuna bakıldığ 1 zaman bu suların tarımsal sulamada yeniden kullanımı toprağa, bitkiye ve yeraltı suyuna doğrudan etki ederken, insana ve insan sağlığına ise dolaylı olarak etki etmektedir. A ğır metaller bitkilerde ve diğer canlıların yapısında doğal olarak belirli limit değerlerde bulunurlar ve yapısal anlamda metabolizmada çeşitli görevler üstlenen elementlerdir. Bunun yanında bazı ağır metallerin ise metabolizmada hiçbir fonksiyonu yoktur ve vücut için zararlıdır. Normal koşullarda insan bünyesinde belirli oranlarda bulunması gayet doğal olan bu metallerin aşırı olan değerleri diğer canlılarda olduğu gibi insanlarda da toksik etki gösterir (Özyürek, 2016).

İnsana olan doğrudan maruziyeti değerlendirmek adına drenaj kanallarının potansiyel etkisi altındaki K7 ve K8 no'lu kuyulara ait OSIB (2017) tarafindan Mart-2016 ve Ekim2016 dönemlerinde yapılan ölçümler, TSE 266 (2005), EPA (2012) ve WHO (2017) gibi ulusal ve uluslararası içme suyu kriterlerine göre mukayese edilerek değerlendirilmiştir. Buna göre; jeotermal kaynak kullanımı sonucu ve tarımsal amaçlı sulama suyunun yeniden kullanılması ile yeraltı suyunda ağır metal bakımından 3 farklı içme suyu kriterine göre içme suyu sınır değerlerini aşan parametreler Al ve Fe olmakla birlikte, 7 ağır metal parametresi ise sınır değerlerin altında kalmıştır (Çizelge 3). Nihai olarak drenaj kanallarındaki $\mathrm{Al}, \mathrm{Cr}, \mathrm{Fe}$, $\mathrm{Mo}, \mathrm{Ni}$, Se ve $\mathrm{V}$ gibi ağır metal kirliliği yeraltı sularını sadece Al ve Fe bakımından etkilemiştir. Ancak ilerleyen zamanda sınır değerleri aşacak parametrelerde artışın olacağ 1 da kaçınılmazdır. 
Çizelge 3. Kuyularda Mart ve Ekim 2016 dönemi izleme verileri ile içme suyu kriterlerine göre nihai durumları (OSIB, 2017).

Table 3. Monitoring data from wells for March and October 2016 and their final status according to drinking water criteria (OSIB, 2017).

\begin{tabular}{|c|c|c|c|c|c|c|c|c|}
\hline \multirow{2}{*}{$\begin{array}{c}\text { Parametre } \\
(\mathrm{mg} / \mathrm{L})\end{array}$} & \multicolumn{2}{|c|}{ Mart 2016} & \multicolumn{2}{|c|}{ Ekim 2016} & \multicolumn{3}{|c|}{ Sınır Değer } & \multirow{2}{*}{ Nihai Durum } \\
\hline & K7 & K8 & K7 & K8 & TSE-266 & EPA & WHO & \\
\hline $\mathrm{Al}$ & 0,088 & 0,232 & 0,21 & 0,01 & 0,2 & 0,05 & 0,1 & Aşı1ldı \\
\hline As & 0,0002 & 0,0002 & 0,001 & 0,001 & 0,01 & 0,01 & 0,01 & Aşılmadi \\
\hline Co & 0,0001 & 0,00034 & 0,0004 & 0,00002 & - & - & - & - \\
\hline $\mathrm{Cr}$ & 0,0135 & 0,0036 & 0,0065 & 0,0026 & 0,05 & 0,1 & 0,05 & Aşılmadı \\
\hline $\mathrm{Fe}$ & 0,135 & 0,230 & 0,25 & 0,03 & 0,2 & 0,3 & 0,3 & Aşıld1-TSE \\
\hline $\mathrm{Mn}$ & 0,0022 & 0,0100 & 0,008 & 0,001 & 0,05 & 0,05 & 0,1 & Aşılmadı \\
\hline Mo & 0,002 & 0,002 & 0,003 & 0,003 & - & - & 0,07 & Aşılmadi \\
\hline $\mathrm{Ni}$ & 0,0009 & 0,002 & 0,005 & 0,001 & 0,02 & - & 0,07 & Aşılmadı \\
\hline $\mathrm{Pb}$ & 0,0010 & 0,0011 & 0,001 & 0,000 & 0,01 & 0,015 & 0,01 & Aşılmadı \\
\hline $\mathrm{Se}$ & 0,0033 & 0,0067 & 0,001 & 0,001 & 0,01 & 0,05 & 0,04 & Aşılmadı \\
\hline V & 0,015 & 0,045 & 0,01 & 0,01 & - & - & - & - \\
\hline
\end{tabular}

Tarımsal topraklarda, metallerin varlı̆̆1 endişe vericidir, çünkü bunlar daha az çözünür formlarda birikme, toprak çözeltisine aktarılma ve daha sonra yeraltı sularını ve mahsul kalitesini bozma potansiyeline sahiptir (Marrugo-Negrete vd., 2017). Tarımsal topraklar ağır metaller bakımından kirlendiği zaman, bunlar bitkiler tarafından alınır ve sonuç olarak bitki dokularında birikir. Bu tür kirlenmiş bitkilerde otlayan ve kirli sulardan içilen hayvanların yanı sıra ağır metal ile kirlenmiş içme sularını ve metallerle kirlenmiş tarım ürünlerini tüketen insanların dokularında biriken metaller doğrudan ve dolaylı olarak toksik etkiye neden olmaktadır (Verma vd., 2013).

\section{SONUÇLAR}

Yeşilnacar vd. (2007) yaptıkları çalışmada Harran Ovası yeraltı suyu kalitesi ve kirlenme potansiyelinin belirlenmesi ve kirlilik haritasının oluşturulmasıyla bir nebze de olsa ovadaki sorunun boyutunu ortaya koymuşlardır. Ovada yapılan bir diğer çalışma ise OSİB (2017) GAP Bölgesi'nde sulamadan dönen suların kontrolü ve yeniden kullanımı için iyileştirilmesinin araştırılması projesidir. Mevcut çalışmada, Harran Ovası'nda bulunan ve Şanlıurfa ilinin tek jeotermal kaynağ Karaali jeotermalinde ve jeotermal suyun deşarj edildiği drenaj kanallarında ağır metal kirliliğinin araştırılması ve yakınındaki yeraltı suyuna olan etkisinin belirlenmesidir. Drenaj kanallarındaki sulama suyunun yeniden kullanılması ile toprak, bitki ve yeraltı suyu ile insan sağlığına olan doğrudan ve dolaylı etkisi belirlenmeye çalışı1mıştır.

Drenaj kanallarında ölçülen ağır metal parametrelerinden $\mathrm{Al}, \mathrm{Cr}, \mathrm{Fe}, \mathrm{Mo}, \mathrm{Ni}$, Se ve V değerleri açısından ilgili taslak yönetmeliğin Tablo 2 listesinde yer alan kriterler aşılmıştır. Ağır metal değerinin yüksek çıkmasının nedeni özellikle çevreden taşınan volkanik kayaçlar ve kireçtaşlarına bağl1 olduğu düşünülmektedir. Ayrıca bir diğer sebep olarak tarımsal ilaçlama ile toprakta biriken metallerin yüzeysel akışla drenaj kanallarına taşınmış olma ihtimali de söz konusu olabilir. As, $\mathrm{Co}, \mathrm{Mn}$ ve $\mathrm{Pb}$ değerleri açısından ise sınır değerler aşılmamıştır. Sb parametresi 
için mevzuatta sınır değer yer almadı̆̆ değerlendirme yapılamamıştır. Harran ovasında ölçüm yapılan bütün ağır metaller bakımından örnekleme noktaları arasında en kirli olan noktanın D11 no'lu nokta, en temiz noktanın ise D12 no'lu nokta olduğu tespit edilmiştir. D11 no'lu nokta jeotermal kaynaklar sonrasinda gelen sular ile sulamadan dönen kirli sulardan oluşmaktayken, D12 no'lu nokta Firat suyuyla sulanan arazilerden elde edilen taze ve nispeten temiz drenaj sularını temsil etmektedir.

Yeraltı sularında ait yapılan ölçümler, TSE 266 (2005), EPA (2012) ve WHO (2017) gibi ulusal ve uluslararası içme suyu kriterlerine göre mukayese edildiğinde jeotermal kaynak kullanımı sonucu ve tarımsal amaçlı sulama suyunun yeniden kullanılması ile içme suyu sınır değerlerini aşan parametreler Al ve Fe olmakla birlikte, 7 ağır metal parametresi ise sınır değerlerin altında kalmıştır (Çizelge 3). Nihai olarak drenaj kanallarındaki Al, $\mathrm{Cr}, \mathrm{Fe}, \mathrm{Mo}, \mathrm{Ni}$, Se ve V gibi ağır metal kirliliği yeraltı sularını sadece Al ve Fe bakımından etkilemiştir.

$\mathrm{Bu}$ çalışma insan maruziyeti bakımından değerlendirildiğinde; sulama suyunun yeniden kullanılması ile toprak, bitki ve yeraltı suyuna taşınan ağır metal kirliliği ile insana ve insan sağlığına dolaylı maruziyetin şu an için yeraltı suyunun tüketimi ile doğrudan maruziyetten daha fazla etki edeceği düşünülmektedir. Ancak ilerleyen süreçte bu ağır metal kirliliğinin yeraltı suyunu da etkileyeceği bir gerçektir. Ova genelinde drenaj kanalları ve özellikle de yakınındaki yeraltı sularında periyodik izlemelere devam edilmesinin yanında toprakta ve bitkilerde ise ağır metal birikimleri için düzenli kontrollerin yapılması önerilmektedir.

\section{EXTENDED SUMMARY}

In Turkey, geothermal resource research shows that there is significant geothermal energy potential that can be considered an alternative because of advantages provided by utilization possibilities, even if not as many as fossil energy resources. Karaali Geothermal Area, which is one of two geothermal springs in Şanliurfa province is located $45 \mathrm{~km}$ southeast of Şanliurfa province in the southeastern Anatolia region and includes the village of Karaali in the Akçakale graben. Karaali geothermal area is located in Harran Plain which has very important agricultural potential for the development of our country. At the same time, it is of great importance because of being the only thermal tourism location and source of greenhouse heating in Şanlıurfa.

Recent studies show that geothermal water is discharged directly or indirectly into the nearest drainage channels after use without control. Therefore, it affects the soil and plants together with groundwater in terms of heavy metal pollution. As some heavy metals spread to the environment, they cause severe disorders in plants, animals and humans depending on their concentration in the environment. Many of the heavy metals and metalcontaining compounds (metalloids) are toxic. Therefore, they can cause undesirable effects and problems even at very low concentrations. The effects of the accumulation of these pollutants in the soil and living organisms may not be immediately (acutely) visible. Therefore, heavy metal accumulation should be closely monitored.

In this study, the aim is to determine the direct and indirect exposure on human health of heavy metal pollution sourced from geothermal area. In this context, seasonal sampling was carried out between October-February 2018 at 6 points in total, including the Karaali geothermal fluid and nearby drainage channels. Heavy metal parameters such as $\mathrm{Al}, \mathrm{As}, \mathrm{Co}, \mathrm{Cr}, \mathrm{Fe}, \mathrm{Mn}, \mathrm{Mo}$, $\mathrm{Ni}, \mathrm{Pb}, \mathrm{Sb}$, Se and $V$ were measured.

As a result, it was determined that $\mathrm{Al}, \mathrm{Cr}$, $\mathrm{Fe}, \mathrm{Mo}, \mathrm{Ni}$, Se and $V$ parameters exceed the limit values in the relevant draft regulations that 
should be taken into consideration for the reuse of water in the drainage channels as agricultural irrigation water. In addition, in $K 7$ and $K 8$ wells near the drainage channels, the limit values were exceeded for $\mathrm{Al}$ and $\mathrm{Fe}$ parameters according to TSE 266, EPA and WHO drinking water criteria. Finally, heavy metal pollution such as $\mathrm{Al}, \mathrm{Cr}, \mathrm{Fe}$, $\mathrm{Mo}, \mathrm{Ni}$, Se and $V$ in the drainage channels affected the wells only in terms of $\mathrm{Al}$ and $\mathrm{Fe}$. It was concluded that at present the indirect exposure of humans and human health due to heavy metal pollution carried to soil, plant and groundwater by reuse of irrigation water is more effective than direct exposure due to consumption of ground water. However, it is also possible that there will be an increase in parameters exceeding the limit values in terms of heavy metal. It is recommended to carry out periodic monitoring of the drainage channels and especially in the nearby wells across the plain and to conduct regular investigations for heavy metal accumulation in soil and plants.

\section{KATKI BELIRTME}

$\mathrm{Bu}$ çalışma, Harran Üniversitesi Bilimsel Araştırma Projeleri (HÜBAP) tarafından 18081 no'lu proje ile desteklenmiştir.

\section{ORCID}

Perihan DERIN (D) https://orcid.org/0000-0002-4920-9804 Ayşegül DEMIR YETiŞ D https://orcid.org/0000-0003-4745-2445 M. İran YEŞILNACAR D https://orcid.org/0000-0001-9724-8683 Pelin YAPICIOĞLU D https://orcid.org/0000-0002-6354-8132

\section{DEĞİNILEN BELGELER / REFERENCES}

APHA, 1998. Standard Methods for the Examination of Water and Wastewater. 20th Edition, Editörler: Clesceri, L.S., Greenberg, A.E.., Eaton, A.D. United Book Press, Baltimore, MD, USA, 4-103.

Arora, M., Kiran, B., Rani, S., Rani, A., Kaur, B., Mittal, N., 2008. Heavy Metal Accumulation in Vegetables Irrigated with Water from different Sources. Food Chemistry, 111, 811-815.
Baba, A., Akkuş, İ., Şaroğlu, F., Özel, N., Yeşilnacar, M.İ., Nalbantçılar, M.T., Demir, M., Gökçen, G., Arslan, Ş., Dursun, N., Yazdani, H., 2015. GAP İlleri Jeotermal Kaynakları Araştırma Projesi. GAP Bölge Kalkınma İdaresi Başkanlığı, Şanlıurfa.

Bahçeci, İ., 2019. Tarımsal Drenaj Sistemleri Ders Notları. Harran Üniversitesi, Ziraat Fakültesi, Tarımsal Yapılar ve Sulama Bölümü - Şanliurfa [http://web.harran.edu.tr/assets/uploads/other/ files/Ziraat Fak\%C3\%BCltesi/SULAMA/ TARIMSAL DRENAJ M\%C3\%9CH.pdf Erișim Tarihi: 08.11.2019]

Çelik, M.A., Gülersoy, A.E., 2013. Güneydoğu Anadolu Projesi'nin (GAP) Harran Ovası tarımsal yapısında meydana getirdiği değişimlerin uzaktan algılama ile incelenmesi. Uluslararası Sosyal Araştırmalar Dergisi, 6 (28), 46-54.

Derin, P., 2019. Karaali (Şanlıurfa) Jeotermal Sahasının Ağır Metal Kirliliği Açısından Araştırılması. Harran Üniversitesi Fen Bilimleri Enstitüsü, Şanlıurfa, Yüksek Lisans Tezi, 73 s., (yayımlanmış).

EPA (United States Environmental Protection Agency), 2009. National Primary Drinking Water Regulations, EPA 816-F-09-004.

Güven, K.C., Öztürk, B., 2005. Deniz Kirliliği. TÜDAV Yayınları, No: 21, İstanbul, $512 \mathrm{~s}$.

Kara, Y., 2005. Bioaccumulation of $\mathrm{Cu}, \mathrm{Zn}$ and $\mathrm{Ni}$ from the Wastewater by Treated Nasturtium Officinale. International Journal of Environmental Science and Technology, 2, 63-67.

Marrugo-Negrete, J., Pinedo-Hernández, J., Díez, S., 2017. Assessment of heavy metal pollution, spatial distribution and origin in agricultural soils along the Sinú River Basin, Colombia. Environmental Research, 154, 380-388.

OSİB, 2017. GAP Bölgesi'nde sulamadan dönen suların kontrolü ve yeniden kullanımı için iyileştirilmesinin araştırılması proje nihai raporu. Orman ve Su İşleri Bakanlığı, Su Yönetimi Genel Müdürlüğü, TÜBİTAK-MAM, Gebze, Kocaeli.

Özyürek, F., 2016. Nevşehir'de Farklı Su Kaynaklarıyla Sulanan Sebzelerde Ağır Metal $(\mathrm{Cd}, \mathrm{Cr}, \mathrm{Cu}, \mathrm{Fe}$, $\mathrm{Ni}, \mathrm{Pb}, \mathrm{Zn}$ ) Birikimi. Nevşehir Hacı Bektaş Veli Üniversitesi, Fen Bilimleri Enstitüsü, Nevşehir, Yüksek Lisans Tezi, 118 s., (yayımlanmış). 
Sabiha-Javied, M.T., Tufai, M., Irfan, N., 2009. Heavy metal pollution from phosphate rock used for the production of fertilizer in Pakistan. Microchemical Journal, 91, 94-99.

TS-266, 2005. Sular-İnsani tüketim amaçlı sular, Türk Standartları Enstitüsü. Nisan. ICS 13.060.20

Verma, R., Dwivedi, P., 2013. Heavy metal water pollution-A case study. Recent research in Science and Technology, 5(5), 98-99.

WHO (World Health Organization), 2017. Guidelines for Drinking Water Quality: Fourth Edition. Incorporating the First Addendum. Geneva. ISBN 978-92-4-154995-0
Yeşilnacar, M.İ., Demir, F., Uyanık, S., Yılmaz, G., Demir, T., 2007. Harran Ovası Yeraltı Suyu Kalitesi ve Kirlenme Potansiyelinin Belirlenmesi. TÜBİTAK Proje No: 104Y188.

Yetiş, R., Atasoy, A.D., Demir Yetiş, A., Yeşilnacar, M.I., 2019. Hydrogeochemical characteristics and quality assessment of groundwater in Balikligol Basin, Sanliurfa, Turkey. Environmental Earth Sciences, 78, 331. 